\title{
Effect of Pterygium Morphology on Recurrence with Preoperative Subconjunctival Injection of Mitomycin-C in Primary Pterygium Surgery
}

\author{
Faisal Aziz Khan and Shafaq Pervez Khan Niazi
}

\begin{abstract}
Objective: To investigate the effect of pterygium morphology on recurrence with preoperative subconjunctival injection of mitomycin-C in primary pterygium surgery.

Study Design: Quasi-experimental study.

Place and Duration of Study: Eye Department, Combined Military Hospital, Malir Cantt, Karachi, from February 2017 to February 2018.

Methodology: On the basis of pterygium morphology, 165 eyes of 165 patients were equally divided into three equal groups of atrophic, intermediate and fleshy pterygia. In each morphology group, length was graded into three groups using limbus, pupil margin and midiris as landmarks. All pterygia received $0.1 \mathrm{ml}$ of mitomycin-C injection in a concentration of $0.15 \mathrm{mg} / \mathrm{ml}$ at 24 hours prior to undergoing a bare sclera surgical excision technique in all cases. All patients were followed up for 12 months. The recurrence rate was recorded in each morphology group. Pearson Chi-Square test was used to compare recurrence rate and morphology group. Fisher's exact test was applied to compare recurrence rate with length and age in each type of morphology.

Results: Among the three morphology groups, the recurrence rate was statistically significant between fleshy and atrophic pterygia $(p=0.01)$ and no significant association was found among other morphology comparisons. Age less than 40 years had a significant effect on recurrence in all morphology groups. Length did not affect the recurrence rate in any of morphology types.

Conclusion: Recurrence of primary pterygium is related to fleshiness of the pterygium and is a significant risk factor for recurrence after preoperative subconjunctival injection of mitomycin- $C$ given at 24 hours before sclera excision.
\end{abstract}

Key Words: Mitomycin-C, Pterygium morphology, Pterygium surgery, Recurrence, Subconjunctival injection.

\section{INTRODUCTION}

Recurrence of pterygium is a frequent source of dissatisfaction for the operating surgeon as well as for the patient. ${ }^{1}$ Preoperative risk factors for recurrence of primary pterygium include younger age of less than 50 years, ${ }^{2}$ higher grade of corneal involvement, ${ }^{3}$ pterygium morphology, ${ }^{4}$ operating surgeon's skill and experience. ${ }^{5}$

Amidst these factors, the morphology of the pterygium has been associated with higher recurrence rate, with fleshy pterygia producing higher recurrence rate than atrophic ones. ${ }^{3}$ Previous studies have correlated the morphology of the pterygium with recurrence by employing various techniques in dealing with the bare sclera after surgical excision. These modalities are conjunctival autograft,4,6 amniotic membrane graft, intraoperative and postoperative Mitomycin-C (MMC) application. 6

Department of Eye, Combined Military Hospital, Malir Cantt, Karachi, Pakistan

Correspondence: Dr. Faisal Aziz Khan, Department of Eye, Combined Military Hospital, Malir Cantt, Karachi, Pakistan E-mail: faisaleyecare@gmail.com

Received: November 07, 2018; Revised: December 21, 2018; Accepted: December 21, 2018
The preoperative use of MMC as a subconjunctival injection into the body of pterygium before surgical excision is another modality in which the recurrence rate is similar to the intraoperative application of MMC. ${ }^{7}$ The incidence and severity of postoperative complications of preoperative subconjunctival injection are comparable to the intraoperative application of MMC. ${ }^{8}$ Compared to intraoperative application of MMC, the preoperative subconjunctival injection into the body of pterygium is advantageous as its concentration does not get diluted in the tear film, there is limited intraocular penetration since the corneal epithelium is intact; and as a result there is more prolonged contact time with the subconjunctival tissue. ${ }^{8}$

Preoperative injection has been given either at one month or 24 hours prior to pterygium removal with neither offering advantage over the other in terms of recurrence and corneoscleral complications. ${ }^{9}$ The one month waiting time adds to the patient discomfort as it becomes a two-stage procedure. ${ }^{9}$

After reviewing the published data, we found that research work on the influence of pterygium morphology and recurrence with the preoperative use of MMC as a subconjunctival injection into the body of pterygium is lacking. Consequently, the rationale of this study was to 
determine whether morphology of the pterygium have an effect on the recurrence of pterygium with the preoperative use of MMC as a subconjunctival injection given at 24 hours prior to the removal of pterygium; considering recurrence as the most serious postoperative complication of pterygium surgery.

The objective of this study was to investigate the effect of pterygium morphology on recurrence with preoperative subconjunctival injection of MMC in primary pterygium surgery.

\section{METHODOLOGY}

This quasi-experimental study was conducted at the Eye Department of Combined Military Hospital, Malir Cantt, Karachi, from February 2017 to February 2018. The study was approved by the Ethical Review Board Committee of the Hospital. Patients attending the outpatient unit of the department were selected for the study. The inclusion criteria was primary pterygium for which surgery was indicated, considering the presence of one of the following criteria: (i) minimal length equal to a point midway between limbus and pupillary margin; (ii) pterygium induced corneal astigmatism; and/or (iii) chronic symptomatic pterygia. The other inclusion criteria were age between 20 and 80 years, male or female gender, nasal or temporal pterygium. Patients having a pseudopterygium, recurrent pterygium, dry eyes syndrome and ocular cicatricial diseases were excluded from the study. On the basis of morphology of pterygium proposed by Tan et al, 10 patients were divided into three equal groups labelled based on its translucency as atrophic (grade T1), intermediate (grade T2) and fleshy (grade T3). A grade T1 (atrophic) pteygium was defined as the grade in which the episcleral vessels underlying the body of pterygium were unobscured and clearly distinguished, while grade T3 (fleshy) was the pterygium in which the underlying episcleral vessels were totally obscured by the fibrovascular tissue of the pterygium; and a pterygium was labelled as grade T2 (intermediate) when its morphology did not fall in grade T1 or T3 categories.10 A sample size of 53 patients in each group was calculated using the WHO calculator so as to detect a significant difference in the recurrence rate between the groups with $90 \%$ power $(\beta=0.10)$, a (twosided) level of significance of $95 \%(\alpha=0.05)$ and anticipated population proportion P1 for grade T3 was 0.33 and anticipated population proportion $\mathrm{P} 2$ for grade T1 was 0.08 .

A total of 165 eyes of 165 patients were included in the study. A written informed consent was obtained from all the patients. After obtaining ocular and systemic history, ocular examination was done which included Snellen visual acuity, manifest refraction, automated keratometry, During slitlamp anterior segment examination, the length of corneal involvement of pterygium was recorded by noting the location of the apex; and graded according to the classification into grade I (between limbus and a point midway between limbus and pupillary margin), grade II (between pupillary margin and a point midway between limbus and pupillary margin) and grade III (crossing pupillary margin).11 Intraocular pressure was checked.

All patients received an injection of MMC into the pterygium at approximately 24 hours before the surgical excision of the pterygium. The surgical modality utilised for all the pterygia was bare sclera technique after excision. Using a $30 \mathrm{G}$ insulin needle, $0.1 \mathrm{ml}$ of 0.15 $\mathrm{mg} / \mathrm{ml}$ concentration of MMC was injected into the body of pterygium after instilling a drop of proparacaine under the operating microscope. The needle was inserted approximately $1.5 \mathrm{~mm}$ away from the limbus into the body of pterygium under aseptic condition. A drop of $0.3 \%$ ofloxacin eye drop was placed after the injection. The patients were examined under the slitlamp examination just preceding surgery. At the slitlamp, the conjunctiva and cornea were stained for epithelial defects and intraocular pressure was checked. All surgeries were performed by one surgeon. The surgery was performed under topical anaesthesia using proparacaine and local infiltration of $0.1 \%$ lignocaine $\mathrm{HCl}$ with 1:100000 adrenaline into the body of the pterygium. The pterygium head was dissected from its corneal edge using No.15 Bard Parker blade till the limbus. The pterygium was separated with blunt dissection from the underlying sclera till the insertion of the medial rectus muscle and also separated from the overlying bulbar conjunctiva. Then the pterygium was excised alongwith its accompanying tenon's fascia. The bare scleral defect was left as such. A tobramycin / dexamethasone ointment was applied and the eye was padded. The eye pad was removed on the first postoperative day and tobramycin/dexamethasone eye drops, three times daily, was prescribed for four weeks. All the patients were examined at one week and then monthly for 12 months. At each examination, the eyes were examined for epithelial defects, corneoscleral thinning, dellen, secondary glaucoma, granuloma and pterygium recurrence. The recurrence was defined as fibrovascular growth of conjunctival tissue extending for more than $1 \mathrm{~mm}$ past the limbus.

Statistical analysis was performed using SPSS version 20.0. Descriptive statistics were calculated for age. Frequencies and percentages were calculated to describe gender distribution. Normality tests were applied for age. Patients were divided into two age groups, one less than 40 years and other 40 years and above, within each morphology group. Recurrence of pterygium was described as frequency and percentage. The recurrence rate of pterygium in each morphology group was calculated. 
Pearson Chi-square test was used to compare the recurrence rate and morphology type. Fisher's exact test was used to compare the recurrence rate between age groups in each type of morphology group. Similarly, Fisher's exact test was also applied to compare the recurrence rate between length groups in each type of pterygium morphology. The tests were 2-tailed and a $p$-value $<0.05$ was considered to be statistically significant.

\section{RESULTS}

The median (IQR) age of the patients were 44 (23) years. Male to female ratio was $3: 1$. The overall recurrence rate was $18.2 \%$. No intraoperative complications were noted.

Postoperatively, out of the 165 patients, one (0.6\%) patient developed scleral thinning, Tenon's granuloma was seen in three $(1.8 \%)$ patients, and two $(1.2 \%)$ patients developed conjunctival avascularity.

The recurrence rate of the pterygium in atrophic group was $9 \%$ ( 5 out of 55 eyes), in pterygia with intermediate morphology 10 eyes out of 55 developed recurrence $(18 \%)$, and in those with fleshy pterygia the recurrence rate was $27.3 \%$ ( 15 out of 55 eyes). The difference in recurrence rate between atrophic and fleshy pterygia group was statistically significant $(p=0.01)$. However, the difference in recurrence rate between atrophic pterygia and intermediate morphology pterygia group was not statistically significant $(p=0.16)$. Similarly, no statistically significant difference in the recurrence rate of pterygium was found between pterygia of intermediate and fleshy morphology $(p=0.25$, Table I).

Comparison of the recurrence rate and age in each morphology group showed a statistically significantly higher recurrence rate of pterygium in patients whose age was less than 40 years in atrophic, intermediate morphology and fleshy pterygium group (Table II). Comparative analysis of the recurrence rate between grade III (pterygium length crossing pupillary margin) and grade I (pterygium length between limbus and a point midway between limbus and pupillary margin) in each morphology group depicted a statistically insignificant association in the atrophic $(p=1.0)$, intermediate morphology $(p=0.09)$, and fleshy pterygia group $(p=0.39)$.

\section{DISCUSSION}

Pterygium is a highly invasive, inflammatory, fibrovascular growth. 12 Clinically, fleshiness of the pterygium is a significant risk factor for recurrence if bare sclera excision is performed. 10 Han et al. precisely quantified the pterygium vascularity preoperatively using automated image analysis and applied a limbal-conjunctival autograft. They found a significantly higher recurrence rate among pterygia whose vascularity index was high $(p<0.001)$ despite the autograft.13 At immunohistochemistry level, it has also been found that active pterygia with thick bodies might be at increased risk of recurrence. ${ }^{14}$ On the contrary, $\mathrm{Ha}$ et al. determined the role of pterygium morphology and recurrence by subdividing the morphology using a grading system proposed by Oh and Kim, 15 into fibrous thickness and vascularity features and separately analyzed each feature with recurrence using digital image acquisition and software image processing. An amniotic membrane graft or conjunctival autograft was sutured in all their cases. Their results depicted that neither the fibrous thickness nor the vascularity affected the recurrence rate. ${ }^{16}$ Similarly in another study by Kwon and Kim, it was reported that the severity of preoperative pterygium morphology, which was based on the same grading system as used by $\mathrm{Ha}$ et al., did not affect the recurrence rate after applying a conjunctival graft in all their cases and selectively applying MMC intraoperatively. 17

Dzunic and his colleagues applied the identical grading system of pterygium morphology, as used in our study; but found no significant association between morphology and recurrence. In their technique, the bare sclera was covered by directly suturing the conjunctival wound edges together after excising the pterygium till the

Table I: Comparison of pterygium morphology and recurrence rate $(n=165)$.

\begin{tabular}{|c|c|c|c|c|c|c|}
\hline \multirow[t]{2}{*}{ Recurrence } & \multicolumn{2}{|c|}{ Atrophic vs Fleshy } & \multicolumn{2}{|c|}{ Atrophic vs Intermediate } & \multicolumn{2}{|c|}{ Intermediate vs Fleshy } \\
\hline & $\mathrm{n}=55$ & $\mathrm{n}=55$ & $n=55$ & $n=55$ & $\mathrm{n}=55$ & $\mathrm{n}=55$ \\
\hline Yes & $5(9 \%)$ & $15(27.3 \%)$ & $5(9 \%)$ & $10(18 \%)$ & $10(18 \%)$ & $15(27.3 \%)$ \\
\hline No & $50(91 \%)$ & $40(72.7 \%)$ & $50(91 \%)$ & $45(82 \%)$ & $45(82 \%)$ & $40(72.7 \%)$ \\
\hline$p$-value & \multicolumn{2}{|c|}{0.01} & \multicolumn{2}{|c|}{0.16} & \multicolumn{2}{|c|}{0.25} \\
\hline
\end{tabular}

Table II: Age group and recurrence rate comparison in each morphology group $(n=165)$.

\begin{tabular}{l|c|c|c|c}
\hline Age group & Recurrence & \multicolumn{3}{|c}{ Age-wise distribution of recurrence rate in each morphology group } \\
\cline { 2 - 5 } & & Atrophic $(\mathrm{n}=55)$ & Intermediate $(\mathrm{n}=55)$ & Fleshy $(\mathrm{n}=55)$ \\
\hline Age less than 40 years & Yes & $4(28.5 \%)$ & $7(33.3 \%)$ & $14(35.8 \%)$ \\
& No & $10(71.5 \%)$ & $14(66.7 \%)$ & $25(64.2 \%)$ \\
\hline Age 40 years and more & Yes & $1(2.4 \%)$ & $3(8.8 \%)$ & $1(6.2 \%)$ \\
& No & $40(97.6 \%)$ & $31(91.2 \%)$ & $15(93.8 \%)$ \\
\hline p-value & & 0.01 & 0.03 & 0.04 \\
\hline
\end{tabular}


caruncle. 18 On the other hand with the identical grading system for morphology as the present, Tan et al. reported that those pterygia whose sclera was left bare after excision, in them morphology was significantly associated with recurrence. 10 The present results are in agreement with $\mathrm{Ha}$ et al.16 despite the fact that their morphology assessment differed from ours as theirs was based on the degree of pterygium vascularity and they only placed a conjunctival autograft without any adjunctive treatment. The results of $\mathrm{Ha}$ et al. and Kwon contradict with the present findings. ${ }^{16,17}$ This may be due to the fact that both utilised a grading system that was based on precise quantification of pterygium vascularity as well as on its thickness for comparing the morphology with recurrence which was different from grading criteria for morphology. With identical grading system as the present, Tan et al. results are in agreement and Dzunic et al. findings disagree with the present findings. ${ }^{10,18}$ These disagreements reported in the previous research work and in our study in the context of morphology; and recurrence may also be due to the fact that each study has used different techniques in dealing with the wound defect after excision which might have affected the relationship between morphology and recurrence.

Length of corneal involvement of pterygium is another risk factor that has been considered to be related to pterygium recurrence. In this contexts a study by Han et al. showed that relative length did affect the recurrence rate when its role was analysed in a univariate manner; but in a multivariate analysis, the length had no effect on recurrence rate. ${ }^{13}$ Likewise, two identical studies which included both primary and recurrent cases found no difference in recurrence rate among pterygia whose length was greater than $1 \mathrm{~mm}$ from the limbus, and pterygia with length within $1 \mathrm{~mm}$ from the limbus after placing a conjunctival graft in all cases and applying MMC in selective cases intraoperatively. 16,17 Dzunic and his colleagues covered the bare sclera after excision with direct closure of conjunctival wound. They reported that the recurrence was higher in medium sized pterygium with length between 3-4 $\mathrm{mm}$ rather than pterygia with length ranging from $5-6 \mathrm{~mm}$; and hence, no correlation existed between size and recurrence in their study. ${ }^{18}$ With regard to previous studies, this study is unique in this respect that we analysed the role of pterygium length in causing recurrence by comparing among each morphology grading system so as to eliminate the role of variation of morphology as a confounding variable and controlling it from affecting the recurrence rate. These findings depicted that the anatomical position of the pterygium on the cornea between fleshy and atrophic pterygia did not affect the recurrence rate with preoperative subconjunctival injection of MMC. These results and those of previous studies support the fact that length is not significantly associated with recurrence irrespective of whether a graft is used or MMC is applied intraoperatively or subconjunctivally or a direct closure is performed to cover the bare sclera.

Age is an important variable that can influence wound healing. ${ }^{19}$ In young subjects, there is rapid re-epithelialisation, aggressive collagen synthesis and angiogenesis as compared to the aged ones. ${ }^{20} \mathrm{It}$ was, therefore, included in the analysis as a risk factor in causing recurrence. In a multivariate analysis using logistic regression model, two identical studies by Kwon et al. and $\mathrm{Ha}$ et al. found that age less than 40 years was a significant risk factor for pterygium recurrence.16,17 Both authors have even suggested that early pterygium excision should not be performed in young age rather the surgical indication should be adjusted according to the patient's age.16,17 Likewise, using a conjunctival graft after pterygium excision in all case, it was found that less than 45 years of age was an important element in affecting the recurrence. ${ }^{21}$ On the contrary, Han et al. reported that age had no significant association with recurrence after applying a graft in all his cases and with bare sclera excision technique. Tan also found that age was not a risk factor. ${ }^{13,10}$ In this study, the cutoff limit for young age was less than 40 years on the basis of previous studies. Past studies had simply analysed the effect of young age on recurrence. Compared to the previous studies, this study is unique of the fact that we analysed the role of age in each morphology grade and found that younger age does affect recurrence significantly, irrespective of the type of morphology. Additionally, this study also enlightens the point that even with preoperative subconjunctival use of MMC, young age still affects the recurrence rate.

The overall recurrence rate in this study with the preoperative subconjunctival injection of MMC given at 24 hours before surgery was $18.4 \%$. The recurrence rate reported in previous research work on the use of MMC as a subconjunctival injection given at one month before surgery in cases of primary pterygium shows wide range with no recurrences, 22,23 to $2.9 \%,{ }^{24} 3.3 \%, 9$ and $4.2 \%$ recurrences. ${ }^{25}$ The failure rate for primary pterygium that receives MMC just 24 hours before surgery has been reported in the literature to be upto $6.7 \% .{ }^{9}$ The presently reported recurrence rate differs widely and is on the higher side from the previous researched data on the basis that previous studies did not analyse the impact of the morphology and have not mentioned the proportion of cases having fleshy, highly vascularised pterygia that can adversely affect the overall recurrence rate of a research work.

\section{CONCLUSION}

Recurrence of primary pterygium is related to fleshiness of the pterygium; and is a significant risk factor for recurrence after preoperative subconjunctival injection 
of MMC given at 24 hours before sclera excision. In addition, young age significantly affects recurrence among all morphological types of pterygium.

\section{REFERENCES}

1. Chow CY, Dunn SP, Heidemann DG. Pterygium. In: Brightbill FS, McDonnel PJ, McGhee CNJ, Farjo AA, Serderavic O (Eds.) Corneal surgery theory technique and tissue. ed $4^{\text {th }}$. China: Mosby Elsevier; 2009:p194.

2. Mahar PS, Manzar N. Risk factors involved in pterygium recurrence after surgical excision. Pak J Ophthalmol 2014; 30:73-7.

3. Mahar PS, Manzar N. Pterygium recurrence related to its size and corneal involvement. J Coll Phy Surg 2013; 23:120-3.

4. Sandra S, Zeljka J, Zeljka VA, Kristian S, Ivana A. The influence of pterygium morphology on fibrin glue conjunctival autografting pterygium surgery. Int Ophthalmol 2014; 34:75-9.

5. Karalezli A, Kucukerdonmez C, Akova YA, Koktekir BE. Does topical bevacizumab prevent postoperative recurrence after pterygium surgery with conjunctival autografting? Int $J$ Ophthalmol 2014; 7:512-6.

6. Kaufman SC, Jacobs DS, Lee WB, Deng SX, Rosenblatt MI, Shtein RM. Options and adjuvants in surgery for pterygium: A report by the American Academy of Ophthalmology. Ophthalmology 2013; 120:201-8.

7. Martins TGS, Costa ALFA, Alves MR, Chammas R, Schor P. Mitomycin C in pterygium treatment. Int J Ophthalmol 2016; 9: 465-8.

8. Zaky KS, Khalifa YM. Efficacy of preoperative injection versus intraoperative application of mitomycin in recurrent pterygium surgery. Indian J Ophthalmol 2012; 60:273-6.

9. Khan FA, Niazi SPK, Awais M, Ishaq M, Akhter N. Effectiveness of preoperative subconjunctival injection of Mitomycin-C in primary pterygium surgery. J Coll Physicians Surg Pak 2017: 27:88-91.

10. Tan DT, Chee SP, Dear KB, Lim AS. Effect of pterygium morphology on pterygium recurrence in a controlled trial comparing conjunctival autografting with bare sclera excision. Arch Ophthalmol 1997; 115:1235-40.

11. Maheshwari S. Pterygium-induced corneal refractive changes. Indian J Ophthalmol 2007; 55:383-6.

12. Di Girolamo N, Coroneo MT, Wakefield D. Active matrilysin (MMP-7) in human pterygia: Potential role in angiogenesis. Invest Ophthalmol Vis Sci 2001; 42:1963-8.
13. Han SB, Jeon HS, Kim M, Lee SJ, Yang HK, Hwang JM, et al. Risk factors for recurrence after pterygium surgery: An image analysis study. Cornea 2016; 35:1097-103.

14. Kim KW, Park SH, Wee SW. Overexpression of angiogenin in pterygium body fibroblasts and its association with proliferative potency. Invest Ophthalmol Vis Sci 2013: 54:6355-62.

15. Oh JH, Kim HK. The effect of preoperative subconjunctival injection of mitomycin $\mathrm{C}$ and triamcinolone in recurrent pterygium. J Korean Ophthalmol Soc 2009; 50:1005-14.

16. Ha SW, Park JH, Shin IH, Kim HK. Clinical analysis of risk factors contributing to recurrence of pterygium after excision and graft surgery. Int J Ophthalmol 2015; 8:522-7.

17. Kwon SH, Kim HK. Analysis of recurrence patterns following pterygium surgery with conjunctival autografts. Medicine (Baltimore) 2015; 94:e518.

18. Dzunic BN, Jovanovic $P$, Petrovic A. Comparative analysis of pterygium clinical characteristics. Acta Facultatis Medicae Naissensis 2009; 26:77-83.

19. Engeland CG, Bosch JA, Cacioppo JT, Marucha PT. Mucosal wound healing: The roles of age and sex. Arch Surg 2006; 141:1193-7.

20. Gosain A, DiPietro LA. Review aging and wound healing. World J Surg 2004; 28:321-6.

21. Aidenloo NS, Motarjemizadeh Q, Heidarpanah M. Risk factors for pterygium recurrence after limbal-conjunctival autografting: A retrospective, single-centre investigation. Jpn J Ophthalmol 2018; 62:349-56.

22. Avisar R, Bar S, Weinberger D. Preoperative injection of mitomycin $\mathrm{C}$ in combined pterygium and cataract surgery. Cornea 2005; 24:406-9.

23. Khakshoor H, Razavi ME, Daneshvar R, Shakeri MT, Ghate MF, Ghooshkhanehi H. Preoperative subpterygeal injection vs intraoperative mitomycin $\mathrm{C}$ for pterygium removal: comparison of results and complications. Am J Ophthalmol 2010; 150: 193-8.

24. Ishtiaq O, Iqbal Z, Naz MA, Ameen SS. Comparison of preoperative and intraoperative Mitomycin $\mathrm{C}$ in prevention of pterygium recurrence and postoperative complications. Pak Armed Forces Med J 2011; 3:210-12.

25. Mandour SS, Farahat HG, Mohamed HM. Preoperative subpterygial mitomycin $C$ injection versus limbal conjunctival autograft transplantation for prevention of pterygium recurrence. J Ocul Pharmacol Ther 2011; 27:481-5. 